\title{
CIRRHOSIS AND CARCINOMA
}

\section{Treatment of cirrhotic rats with epidermal growth factor and insulin accelerates liver DNA synthesis after partial hepatectomy}

\author{
MASAJI HASHIMOTO, PIYUSH C KOTHARY AND FREDERIC E ECKHAUSER AND \\ STEVEN E RAPER
}

Department of Surgery, University of Michigan, Ann Arbor, Michigan, USA

\begin{abstract}
Prevention of postoperative hepatic failure is important after hepatic resection. In patients with cirrhosis, impaired liver function and regenerative capacity after major hepatic resection are associated with increased morbidity and mortality. In this study, a combination of epidermal growth factor (EGF) and insulin were used as hepatotrophic factors in an attempt to stimulate DNA synthesis after $70 \%$ hepatectomy (HTX). Regenerative capacity was evaluated in normal and cirrhotic rat liver by measuring DNA synthesis in vivo. Micronodular liver cirrhosis was established by the simultaneous oral administration of $\mathrm{CCl}_{4}$ and phenobarbital. Epidermal growth factor plus insulin was injected subcutaneously immediately after and $12 \mathrm{~h}$ after HTX or sham operation was performed. Rats were killed $24 \mathrm{~h}$ after the operation and liver regeneration was estimated by $\left[{ }^{3} \mathrm{H}\right]$-thymidine incorporation into DNA as well as an autoradiographic nuclear labelling index. Hepatectomy increased $\left[{ }^{3} \mathrm{H}\right]$-thymidine incorporation significantly in both normal and cirrhotic rats. In cirrhotic rats, $\left[{ }^{3} \mathrm{H}\right]$-thymidine incorporation after HTX was significantly lower than in normal rats and administration of a combination of EGF and insulin after HTX enhanced $\left[{ }^{3} \mathrm{H}\right]$-thymidine incorporation. In conclusion, DNA synthesis $24 \mathrm{~h}$ after HTX is decreased in cirrhotic rats compared with normal rats and EGF supplementation with insulin accelerates DNA synthesis in hepatectomized cirrhotic rats. The data suggest that administration of combinations of exogenous hepatotrophic factors may play a useful role in the treatment of cirrhotic patients undergoing major hepatic resection.
\end{abstract}

Key words: epidermal growth factor, experimental liver cirrhosis, insulin, liver regeneration.

\section{INTRODUCTION}

Partial hepatic resection is a mainstay of treatment for liver tumours; however, many tumours arise in the setring of cirrhosis and diminished hepatic reserve. Normal liver usually has sufficient regenerative capacity to permit resection of up to $70 \%$ of the total liver cell mass. In liver cirrhosis, impaired liver function and poor regenerative capacity after hepatectomy (HTX) leads to increased morbidity and mortality. ${ }^{1,2}$ There have been few attempts to improve hepatic regeneration in the cirrhotic liver. ${ }^{3,4}$ Utilizing a rat liver model of micronodular cirrhosis, established by the simultaneous oral administration of carbon tetrachloride $\left(\mathrm{CCl}_{4}\right)$ and phenobarbital, supplemental transforming growth factor alpha (TGF $\alpha$ ) enhanced liver regeneration as measured by in vivo $\left[{ }^{3} \mathrm{H}\right]$-thymidine incorporation into DNA. ${ }^{4}$ Epidermal growth factor (EGF) is an hepatotrophic factor which promotes DNA synthesis in rat isolated hepatocytes and regenerating rat liver after 70\% HTX $^{5-7}$ and which shares amino acid homology with $\mathrm{TGF} \alpha{ }^{8}$ Epidermal growth factor has been shown to have synergistic effects on liver regeneration when supplemented with insulin or glucagon in normal rats in vivo. ${ }^{7}$ To determine if EGF alone or in combination with insulin increased DNA synthesis in cirrhotic rat liver, hepatic regeneration was evaluated by measurement of liver DNA synthesis using two independent parameters, $\left[{ }^{3} \mathrm{H}\right]$-thymidine incorporation into DNA and a nuclear labelling index. ${ }^{4,9}$

Correspondence: Masaji Hashimoto, The Department of Digestive Surgery, Toranomon Hospital, 2-2-2, Toranomon, Minatoku, Tokyo 105-8470, Japan. Email: <nobukohashi-ind@umin.ac.jp>

Accepted for publication 20 June 1998. 


\section{METHODS}

\section{Chemicals}

Epidermal growth factor (fragment 20-31; EGF) and bovine insulin were purchased from Sigma Chemical Co. (St Louis, MO, USA). [Methyl $-{ }^{3} \mathrm{H}$ ]-thymidine (37 MBq/mL) was from Amersham (Arlington Heights, II, USA).

\section{Establishment of cirrhosis in a rat model}

Male Wistar rats (150-200 g) were obtained from Charles River Laboratories (Wilmington, MA, USA). Micronodular cirrhosis was established according to the method of Proctor and Chatamra, by the simultaneous oral administration of $\mathrm{CCl}_{4}$ and phenobarbital, which increases the sensitivity of the liver to $\mathrm{CCl}_{4}$ by induction of the microsomal hydroxylating enzyme system. ${ }^{10}$ Rats were given phenobarbital sodium $(35 \mathrm{mg} / \mathrm{dL})$ in drinking water. After treatment for 10-14 days with phenobarbital sodium, the rats weighed $250-300 \mathrm{~g}$. The rats were anaesthetized with isoflurane and oxygen anaesthesia ${ }^{11}$ and $\mathrm{CCl}_{4}$ was administered once a week at midday using a curved feeding needle (16 gauge). After the beginning of $\mathrm{CCl}_{4}$ feeding, bodyweight was measured daily. The initial dose of $\mathrm{CCl}_{4}$ was $0.04 \mathrm{~mL}$ and successive doses were administered according to daily weight fluctuations in each rat. If bodyweight increased, the dose of $\mathrm{CCl}_{4}$ was increased $0.04 \mathrm{~mL}$ per week. If bodyweight decreased, administration of $\mathrm{CCl}_{4}$ was decreased to $0.02 \mathrm{~mL}$ or stopped for the week. Administration of $\mathrm{CCl}_{4}$ lasted for 10 weeks and phenobarbital was continued throughout the period of $\mathrm{CCl}_{4}$ gavage. Both $\mathrm{CCl}_{4}$ and phenobarbital were discontinued at least 2 weeks before the operation.

\section{Partial hepatectomy and sham operation}

Cirrhotic and normal rats were anaesthetized by isoflurane $/ \mathrm{O}_{2}$ anaesthesia ${ }^{11}$ and subjected to sham operation or $70 \%$ hepatectomy. Sham rats were subjected to laparotomy and manipulation of the liver. Hepatectomy was performed after the method of Higgins and Anderson between $08: 00$ and 12:00 $\mathrm{h}$ and resected liver was weighed. ${ }^{12}$

\section{Measurement of DNA synthesis}

Sham-operated and hepatectomized normal and cirrhotic rats were randomly placed in one of four groups. Group A, sham operated, no treatment (normal rats $n=9$, cirrhotic rats $n=6$ ); group B $70 \% \mathrm{HTX}$, no treatment (normal rats $n=9$, cirrhotic rats $n=7$ ); group $C$ $70 \%$ HTX, subcutaneous injection of EGF $(30 \mathrm{nmol} / \mathrm{kg}$ ) just after and $12 \mathrm{~h}$ after $70 \%$ HTX (normal rats $n=3$, cirrhotic rats $n=3$ ); group D $70 \%$ HTX, subcutaneous injection of EGF and insulin ( $30 \mathrm{nmol} / \mathrm{kg}$ and $0.2 \mathrm{nmol} / \mathrm{kg}$ ) just after and $12 \mathrm{~h}$ after HTX (normal rats $n=4$, cirrhotic rats $n=5$ ).
All rats were killed $24 \mathrm{~h}$ after the operation and the remnant liver and spleen were excised and weighed. Blood samples were collected from the inferior vena cava and serum albumin, total bilirubin and glucose were measured using commercial kits (Sigma Chemical Co., St Louis, MO, USA). Serum insulin was measured by radioimmunoassay as performed by the Michigan Diabetes Research and Training Center. Liver DNA synthesis $24 \mathrm{~h}$ after hepatectomy was assessed using $\left[{ }^{3} \mathrm{H}\right]$-thymidine incorporation. $\left[{ }^{3} \mathrm{H}\right]$-Thymidine was injected intravenously $1 \mathrm{~h}$ before the rats were killed. ${ }^{4,8}$ A $0.5 \mathrm{~mL}$ aliquot of liver homogenate (using a Douncetype homogenizer; Sigma) was precipitated with icecold $10 \%$ trichloroacetic acid twice and $70 \%$ ethanol once. $\left[{ }^{3} \mathrm{H}\right]$-Thymidine radioactivity in the precipitate was measured with a Beckman LS 6000LL liquid scintillation counter (Beckman Instruments Inc., Fullerton, CA, USA). A separate $0.1 \mathrm{~mL}$ aliquot was analysed to measure DNA using a modified diphenylamine reaction for desoxypentose. ${ }^{13}$ Data were expressed as c.p.m. $/ \mu \mathrm{g}$ DNA. To minimize variations in the specific activity of the lots of $\left[{ }^{3} \mathrm{H}\right]$-thymidine used, $\left[{ }^{3} \mathrm{H}\right]$-thymidine incorporation into DNA was expressed as a percentage of $\left[{ }^{3} \mathrm{H}\right]$-thymidine incorporation into DNA of shamoperated, non-cirrhotic rat liver.

To corroborate the observed results of $\left[{ }^{3} \mathrm{H}\right]-$ thymidine incorporation into DNA, autoradiographic analysis was performed and a nuclear labelling index was calculated. Tissue samples were fixed in $10 \%$ neutral-buffered formalin and embedded in paraffin blocks. Sections were cut, dipped in Kodak NTB-3 emulsion (Eastman Kodak, Rochester, NY, USA) and exposed for 4 weeks. Slides were developed in Dektol, counterstained with haematoxylin and eosin and analysed under the microscope with a $40 \times$ objective lens. Approximately 1000 nuclei were scored per experimental condition and the percentage of total nuclei positive for silver grains was used to calculate the labelling index.

\section{Statistical analysis}

All values shown represent the mean \pm SEM. Student's $t$-test was used for comparing group means. The level of significance was accepted at $P<0.05$.

\section{RESULTS}

\section{Establishment of liver cirrhosis in rats}

Thirty-four rats were treated with $\mathrm{CCl}_{4}$ and phenobarbital. These rats gained significantly less weight than untreated rats (Fig. 1). Overall mortality was 18\% (6/34). All animals treated had macroscopic changes of the liver compatible with micronodular cirrhosis. Ascites developed during $\mathrm{CCl}_{4}$ treatment in five treated rats $(15 \%)$ but disappeared when the dose of $\mathrm{CCl}_{4}$ was reduced or stopped. Three treated rats $(9 \%)$ were noted to have ascites at the time of operation. Abdominal wall or intra-abdominal collateral vessels or a dilated splenic 


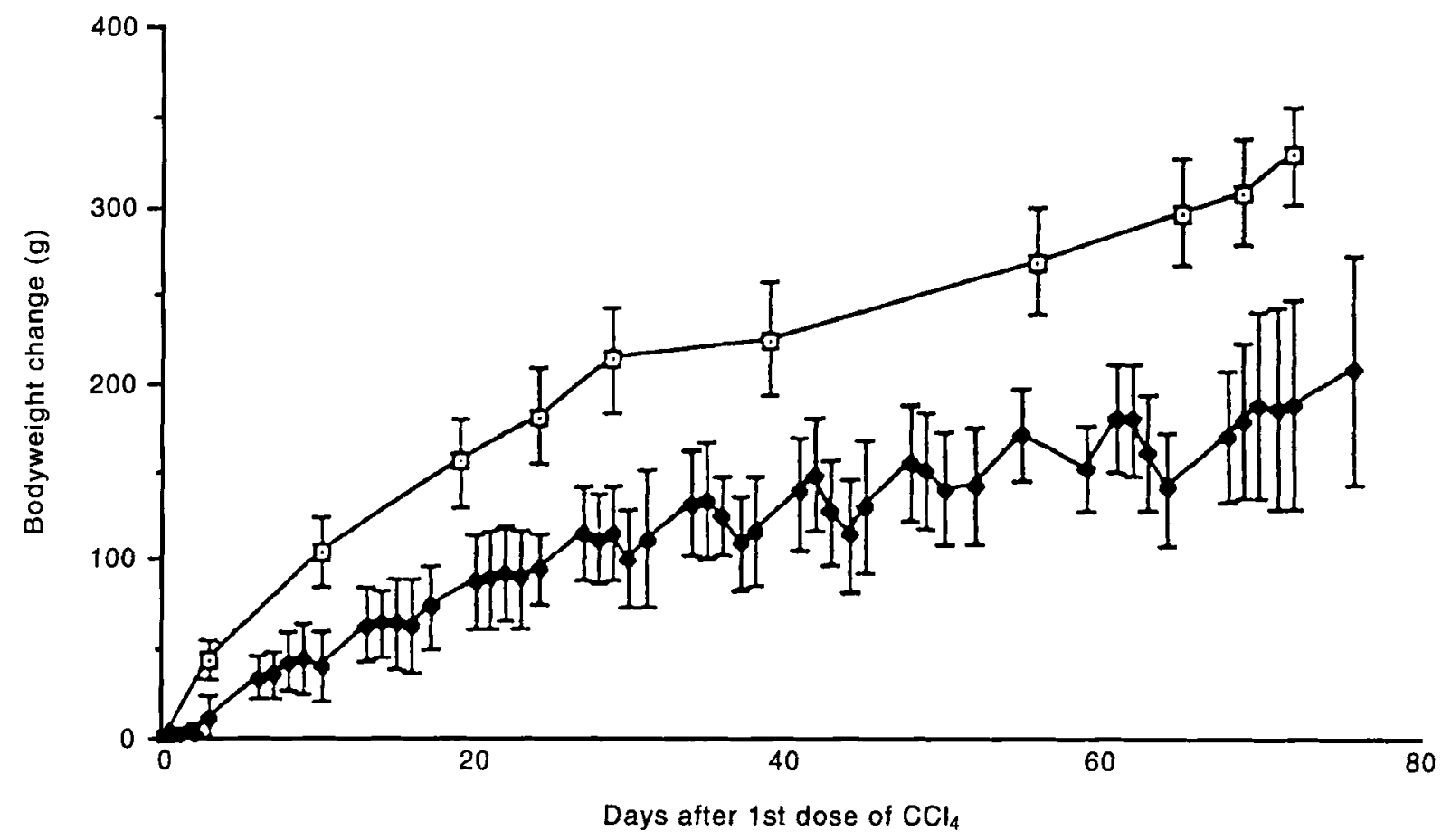

Figure 1 Bodyweight change in experimental animals. All rats were weighed daily after beginning the administration of carbon tetrachloride $\left(\mathrm{CCl}_{4}\right)$. Bodyweight change, compared with starting bodyweight, is expressed on the ordinate. Points are means of cirrhotic rats $(\bullet, n=16)$ or normal controls $(\square, n=5)$. Error bars represent SEM.

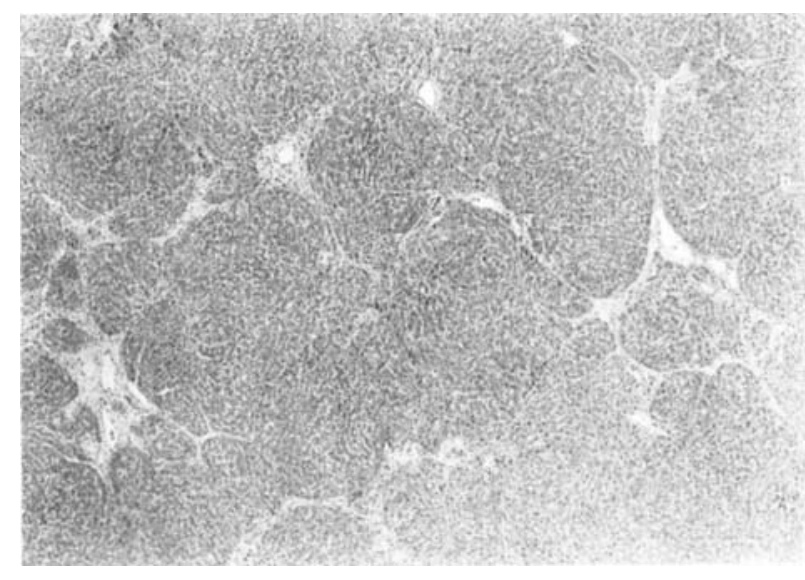

Figure 2 Histology of $\mathrm{CCl}_{4}$-treated cirrhotic rat liver. This section of liver demonstrates established micronodules of liver separated by the thick bands of fibrous scar (Mallory's trichrome stain).

vein were observed in all rats. The overall effectiveness of this method for creating liver cirrhosis was $82 \%$ (28/34). Figure 2 is representative of the typical microscopic features of cirrhosis found in these rat livers.

\section{Characteristics of rats with liver cirrhosis}

To corroborate the gross and microscopic features of cirrhosis in the treated rats, selected biological and
Table 1 Biological and biochemical parameters of experimental animals

\begin{tabular}{lcc}
\hline & $\begin{array}{c}\text { Normal rats } \\
(n=25)\end{array}$ & $\begin{array}{c}\text { Cirrhotic rats } \\
(n=21)\end{array}$ \\
\hline $\begin{array}{l}\text { Bodyweight }(\mathrm{g}) \\
\text { Anterior lobe of liver }(\mathrm{g} / 100 \mathrm{~g}\end{array}$ & $589 \pm 12$ & $463 \pm 19^{\star}$ \\
$\quad$ bodyweight) & & \\
Spleen (mg/100 $\mathrm{g}$ bodyweight) & $220 \pm 8$ & $286 \pm 28^{\star}$ \\
Albumin (g/dL) & $4.00 \pm 0.20$ & $3.41 \pm 0.16^{\star}$ \\
Total bilirubin (mg/dL) & $0.15 \pm 0.05$ & $0.40 \pm 0.10^{\star}$ \\
\hline
\end{tabular}

Data are expressed as mean $\pm S E M .{ }^{\star} P<0.05$ versus normal rats.

biochemical parameters were measured (Table 1). The splenic weight of cirrhotic rats was greater than normal rats. Serum albumin of cirrhotic rats at time of death was less than normal rats. The serum total bilirubin of cirrhotic rats at death was greater than in normal rats.

Insulin levels in normal or cirrhotic rats subjected to $70 \%$ hepatectomy treated with EGF alone or EGF plus insulin were lower than in normal or cirrhotic shamoperated rats (Table 2). Subcutaneous injection of insulin $(0.2 \mathrm{nmol} / \mathrm{kg})$ had no effect on plasma insulin levels between EGF-treated rats and EGF plus insulintreated rats. The serum glucose level after death is shown in Table 2. The glucose level of rats treated with $70 \%$ HTX, EGF and insulin was significantly less than in normal sham rats. 
Table 2 Serum insulin and glucose level $24 \mathrm{~h}$ after operation

\begin{tabular}{lcccccc}
\hline & \multicolumn{2}{c}{ Insulin $(\mu$ units/mL) } & \multicolumn{3}{c}{ Glucose (mg/dL) } \\
& Sham & HTX +EGF & HTX + EGF + Ins & Sham & HTX+EGF & HTX+EGF+Ins \\
\hline Normal rats & $12.6 \pm 1.7$ & $6.2 \pm 0.6^{\star}$ & $5.0 \pm 1.0^{\star}$ & $156 \pm 9$ & $136 \pm 3$ & $113 \pm 14^{\star}$ \\
Cirrhotic rats & $18.8 \pm 2.7$ & $7.6 \pm 0.9^{\star}$ & $8.8 \pm 1.0^{\star}$ & $143 \pm 1$ & $134 \pm 13$ & $123 \pm 14$ \\
\hline
\end{tabular}

Data are expressed as mean \pm SEM. ${ }^{\star} P<0.05$ versus sham-operated rats in each group. HTX, $70 \%$ hepatectomy; EGF, epidermal growth factor; Ins, insulin.

\section{DNA synthesis after sham operation and $70 \%$ hepatectomy}

Twenty-four hours after $70 \%$ HTX, $\left[{ }^{3} \mathrm{H}\right]$-thymidine incorporation into the liver of normal rats was significantly increased from $100 \pm 3 \%$ (normal sham) to $928 \pm 148 \%$, which was 9.3 -fold that of normal sham rats (Fig. 3a). In rats with normal liver, exogenous EGF without supplemental insulin did not enhance $\left[{ }^{3} \mathrm{H}\right]-$ thymidine incorporation after $70 \%$ HTX $(857 \pm 101 \%)$, whereas exogenous EGF with insulin did (1625 \pm $519 \%$ ), but not significantly (Fig. 3a). After 70\% HTX in cirrhotic rats, $\left[{ }^{3} \mathrm{H}\right]$-thymidine incorporation into the liver also significantly increased from $77 \pm 8 \%$ (cirrhotic sham) to $284 \pm 59 \%$ (cirrhotic HTX), 3.7-fold that of cirrhotic sham rats (Fig. 3b). These levels of $\left[{ }^{3} \mathrm{H}\right]-$ thymidine incorporation were significantly lower than in rats with normal liver $(928 \pm 148 \%)$. The combination of exogenous EGF and insulin significantly improved $\left[{ }^{3} \mathrm{H}\right]$-thymidine incorporation in cirrhotic rat liver (284 \pm 59 vs $706 \pm 186 \%$ ). Exogenous EGF alone had no growth-promoting effect on cirrhotic liver after $70 \%$ HTX (204 $\pm 57 \%$ vs $284 \pm 59 \%$ ).

\section{Thymidine autoradiography}

To support the results of $\left[{ }^{3} \mathrm{H}\right]$-thymidine incorporation, autoradiography was performed and a nuclear labelling index was calculated for both normal and cirrhotic rat liver. Over 1000 nuclei were analysed in tissue sections of individual or duplicate rats with normal or cirrhotic liver subjected to sham or $70 \% \mathrm{HTX}$. In rats with normal liver subjected to sham or $70 \% \mathrm{HTX}$, the labelling index was $<1$ and $23 \%$, respectively. Qualitatively, no positive nuclei were seen in cirrhotic rats subjected to sham hepatectomy. In cirrhotic liver from $70 \%$ HTX, the labelling index was $5 \%$. A further marked increase in the labelling index of liver from hepatectomized cirrhotic rats treated with supplemental EGF and insulin (14\%) was also noted. Representative autoradiographs of regenerating cirrhotic rat liver treated with EGF and insulin or without treatment are shown in Fig. 4(a,b).

\section{DISCUSSION}

Previous experiments using the cirrhotic rat model described in this report have shown a beneficial effect of transforming growth factor $\alpha$ (TGF $\alpha$ ) on DNA syn-

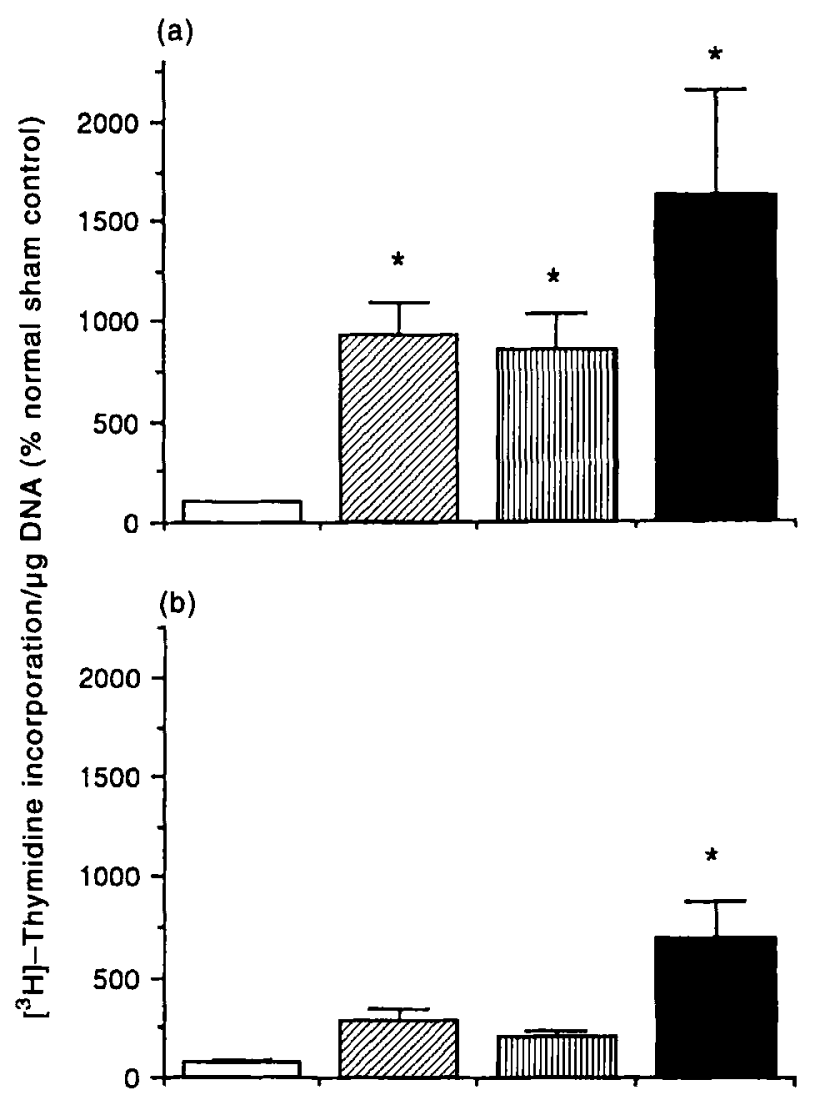

Figure 3 (a) $\left[{ }^{3} \mathrm{H}\right]$-Thymidine incorporation into normal rat liver $24 \mathrm{~h}$ after hepatectomy. In rats with normal liver, $\left[{ }^{3} \mathrm{H}\right]-$ thymidine incorporation was significantly increased when sham hepatectomy $(\square)$ was compared to $70 \%$ hepatectomy (HTX, $\left.\square ;{ }^{\star} P<0.05\right)$. Exogenous EGF with $(\square)$ or without

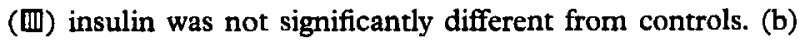
$\left[{ }^{3} \mathrm{H}\right]$-Thymidine incorporation into cirrhotic rat liver $24 \mathrm{~h}$ after hepatectomy. In hepatectomized cirrhotic rats, $\left[{ }^{3} \mathrm{H}\right]$-thymidine incorporation into saline-treated liver was significantly increased from $77 \pm 8 \%$ (sham, $\square$ ) to $284 \pm 59 \%$ (70\% $\mathrm{HTX}$, $\square ; P<0.05$. Exogenous EGF plus insulin $(\square)$ increased $\left[{ }^{3} \mathrm{H}\right]-$ thymidine incorporation to $706 \pm 186 \%$ when compared with saline-treated cirrhotic liver subjected to $70 \%$ HTX $\left({ }^{\star} P<\right.$ 0.05). Exogenous EGF alone (四) had no significant effect on $\left[{ }^{3} \mathrm{H}\right]$-thymidine incorporation into cirrhotic liver after $70 \%$ HTX.

thesis after $70 \% \mathrm{HTX}^{4}$ The phenobarbital/ $\mathrm{CCl}_{4}$ cirrhotic rat model used in the present study was relatively easy to create and established micronodular cirrhosis with a high yield. ${ }^{10}$ The characteristic features of liver histology, splenomegaly and dilated portal collateral cir- 


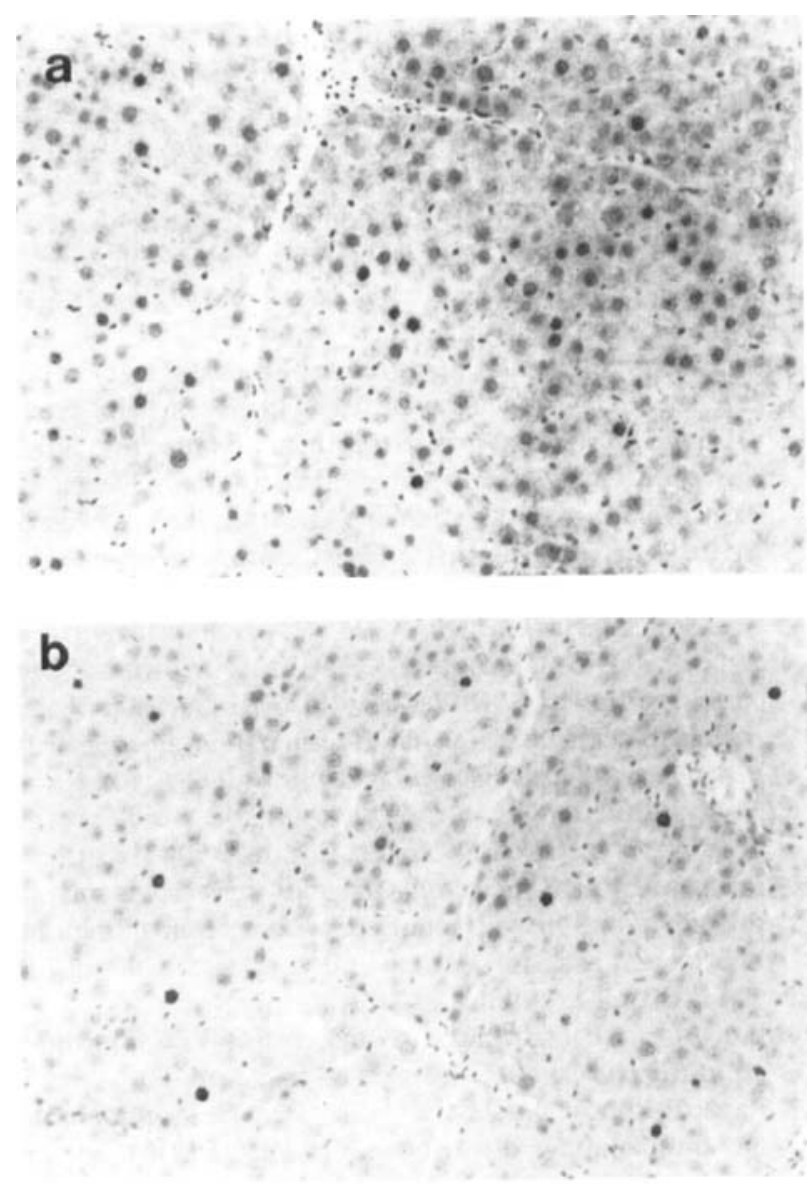

Figure 4 Autoradiographs of $\left[{ }^{3} \mathrm{H}\right]$-thymidine incorporated into cirrhotic rat liver. Representative autoradiographs of $70 \%$ hepatectomized cirrhotic rat liver treated with (a) epidermal growth factor and insulin or (b) without treatment.

culation were similar to those seen in humans with cirrhotic liver and portal hypertension. Hypoalbuminaemia and hyperbilirubinaemia are compatible with impaired liver function as well as structure. In addition, the present study confirms impaired liver DNA synthesis after $70 \% \mathrm{HTX}$ in this cirrhotic rat model.

In normal liver, the rate of DNA synthesis after $70 \%$ HTX reaches a maximum at $24 \mathrm{~h}$ after operation and in cirrhotic liver the process of liver regeneration after $70 \%$ HTX was prolonged. ${ }^{1,2,14}$ In this study, $\left[{ }^{3} \mathrm{H}\right]-$ thymidine incorporation into DNA $24 \mathrm{~h}$ after $70 \%$ HTX was used to evaluate liver regeneration. This parameter has been established to be a useful indicator of the effect of growth factors on cell proliferation in a variety of experimental systems. ${ }^{3,4,9}$ To minimize variation in the specific activity of the lots of $\left[{ }^{3} \mathrm{H}\right]$-thymidine used, $\left[{ }^{3} \mathrm{H}\right]$-thymidine incorporation into DNA was expressed as a percentage of $\left[{ }^{3} \mathrm{H}\right]$-thymidine incorporation into DNA of sham-operated normal rat liver and liver regeneration in both normal and cirrhotic rats could be evaluated quantitatively.

We hypothesized that EGF could be used as an hepatotrophic factor in cirrhotic rat liver. In the experiments reported here, the combination of EGF and insulin enhanced liver DNA synthesis in cirrhotic rats. Some- what unexpectedly, treatment of rats with EGF alone (30 nmol $/ \mathrm{kg}$ ) did not result in improved DNA synthesis after $70 \% \mathrm{HTX}$ in normal or cirrhotic rats, which is consistent with the results of Olsen et al. ${ }^{7}$ Epidermal growth factor required supplemental insulin or glucagon to accelerate liver DNA synthesis after hepatectomy in normal rats; ${ }^{7}$ hence, treatment with EGF and insulin were used in this study. We chose the dose of EGF, $30 \mathrm{nmol} / \mathrm{kg}$, in accordance with the literature. ${ }^{\text {? }}$ Rasmussen et al. reported that a higher dose of EGF $(48 \mathrm{nmol} / \mathrm{kg})$ was ineffective, but that smaller doses can stimulate liver regeneration: the cause of this has not been elucidated. ${ }^{15}$ Two normal non-hepatectomized rats (normal sham) were treated with EGF ( $30 \mathrm{nmol} / \mathrm{kg}$ ) and insulin $(0.2 \mathrm{nmol} / \mathrm{kg})$ and had a $\left[{ }^{3} \mathrm{H}\right]$-thymidine uptake of $84 \pm 17 \%$, which indicated that this treatment did not stimulate DNA synthesis in non-HTX rats.

Although insulin is an hepatocyte growth modulator, a number of lines of evidence suggest that treatment with insulin alone has limited or no benefit in normal regenerating liver. ${ }^{15}$ Insulin is considered to be essential in liver regeneration and is transported into liver during the process of liver regeneration. ${ }^{16}$ Insulin levels are reported to be high in cirrhotic patients and peripheral glucose metabolism suggests an impaired insulin response. ${ }^{17,18}$ Insulin-stimulated glycogen formation has been shown to be markedly impaired. ${ }^{19}$ D'Arville et al. reported that insulin levels of $\mathrm{CCl}_{4}$ /phenobarbitalinduced cirrhotic rats were not significantly altered when compared with phenobarbital-treated rats. ${ }^{20}$ Shankar et al. reported that insulin levels in thioacetamide-induced cirrhotic rats were significantly higher than in normal rats. ${ }^{21}$ There may be a disturbance of the uptake of insulin in cirrhotic liver, possibly by receptor-mediated mechanisms. ${ }^{21}$ After partial hepatectomy, insulin levels have been reported to decline and the administration of exogenous insulin results in little or no regenerative capacity. ${ }^{8,16}$ In normal rats, decreased insulin and elevated glucagon levels have characterized the hepatic proliferative state. ${ }^{16}$ In the present study, insulin levels in hepatectomized rats were significantly lower than in sham-operated rats with normal or cirrhotic liver and serum insulin and glucose levels were measured in treated and untreated normal and cirrhotic rats and found to be unchanged by the doses of insulin administered. Confirming the findings of the previously mentioned studies, insulin levels in cirrhotic sham rats were increased when compared with normal sham rats. The hyperinsulinaemia seen in these cirrhotic rats was not observed to have a cooperative effect with EGF in the acceleration of DNA synthesis. With regards to the effect of insulin alone on liver regeneration, one cirrhotic rat, treated preliminarily only with insulin $(0.2$ $\mathrm{nmol} / \mathrm{kg}$ ), had a $\left[{ }^{3} \mathrm{H}\right]$-thymidine uptake level of $398 \%$ of the normal sham-control rat compared to salinetreated hepatectomized cirrhotic rats at a level of $284 \pm$ $59 \%$. This was in contrast to the data on EGF and insulin, which gave a thymidine uptake value of $706 \pm$ $186 \%$. Due to this preliminary result and hyperinsulinaemia in cirrhotic rats, we did not use insulin alone on cirrhotic rats. ${ }^{7,18}$

There are few studies which correlate the effect of hepatotrophic factors in cultured hepatocytes and in 
vivo studies. In monolayer cultures of isolated hepatocytes, EGF alone has a stimulatory effect on DNA synthesis and EGF supplemented by insulin markedly accelerates DNA synthesis. ${ }^{5,22}$ The observed differences in the effects of EGF on isolated hepatocytes and hepatocytes in vivo are not well understood. Cellular density, or contact inhibition, the hormonal milieu and innervation of the liver in situ and damage during cell isolation might all play a role in the divergent responses seen in isolated hepatocytes and liver in vivo.

Epidermal growth factor and TGF $\alpha$ are similar in that they share a $33-44 \%$ homology in amino acid sequence and bind the same cell surface receptor. ${ }^{7,23}$ Transforming growth factor $\alpha$ has a limited effect on liver regeneration in normal rats, but does have a stimulatory effect in cirrhotic liver. ${ }^{4}$ Epidermal growth factor alone has no effect in cirrhotic liver. In vivo, TGF $\alpha$, acting in an autocrine manner, appears to be the physiological peptide hormone and EGF, acting via either an endocrine or paracrine mechanism, also appears to be the physiological peptide hormone. ${ }^{24,25}$ The reasons for the disparity in the effects of EGF and TGF $\alpha$ are not known. The effects of EGF and TGF $\alpha$ on liver regeneration cannot be quantitatively compared, because the true physiological doses are not known. Further, although EGF and TGF $\alpha$ bind the same receptor in plasma membranes, ${ }^{8}$ there is evidence that EGF and TGF $\alpha$ have different post-receptor pathways of signal transduction. Insulin appears necessary for normal signal transduction by EGF. ${ }^{26,27}$ It is tempting to speculate that the transforming properties of $\mathrm{TGF} \alpha$ in vitro may be related to the lack of a requirement for additional regulatory factors, such as insulin. One potential drawback in the use of these growth factors in clinical trials is the potential for neoplastic transformation. Undetectable neoplasm or metastases in the remnant liver might be stimulated to grow by treatment of growth factors.

In conclusion, DNA synthesis $24 \mathrm{~h}$ after $70 \% \mathrm{HTX}$ was significantly decreased in cirrhotic rats compared with normal rats. Combined treatment with EGF and insulin accelerated DNA synthesis in hepatectomized cirrhotic rats. Ultimately, such a combination of growth factor therapy may prove useful in the support of cirrhotic liver where regeneration must occur to allow patient survival.

\section{ACKNOWLEDGEMENT}

This work was supported by National Institute of Health Grant RO 1 DK 47811 (SER).

\section{REFERENCES}

1 Rabinovici $\mathrm{N}$, Wiener $\mathrm{E}$. Liver regeneration after partial hepatectomy in carbon tetrachloride-induced cirrhosis in the rat. Gastroenterology 1961; 40: 416-22.

2 Nagasue N, Yukaya H, Ogawa Y, Kohno H, Nakamura T. Human liver regeneration after major hepatic resection. Ann. Surg. 1987; 206: 30-9.
3 Urakawa T, Azumi Y, Nagahata Y et al. Study of 16,16dimethyl prostaglandin $E_{2}$ for prevention of stress ulcer after hepatectomy of experimental cirrhotic liver and its influence on hepatic regeneration. Scand. $\%$ Gastroenterol. 1990; 25: 647-55.

4 Kokudo N, Kothary PC, Eckhauser FE, Raper SE. Transforming growth factor alpha (TGF $\alpha$ ) improves DNA synthesis after hepatectomy in cirrhotic rats. 7 . Surg. Res. 1992; 52: 648-55.

5 Bucher NRL, Patel U, Cohen S. Hormonal factors concerned with liver regeneration. In: Porter R, Whelan J, eds. Hepatotrophic Factors (Ciba Foundation Symposium; New Series 55). Amsterdam: Elsevier, 1978; 95-107.

6 Francavilla A, Ove P, Polimeno L, Sciascia C, Coetzee ML, Starzl TE. Epidermal growth factor and proliferation in rat hepatocytes in primary culture isolated at different times after hepatectomy. Cancer Res. 1986; 46: 1318 23.

7 Olsen PS, Boesby S, Kirkegaard P et al. Influence of epidermal growth factor on liver regeneration after partial hepatectomy in rats. Hepatology 1988; 8: 992-6.

8 Massague J. Epidermal growth factor-like transforming growth factor. $f$. Biol. Chem. 1983; 258: 13 606-13.

9 Bucher NLR, Swaffield MN. The role of incorporation of thymidine into deoxyribonucleic acid of regenerating rat liver in relation to the amount of liver excised. Cancer Res. 1964; 24: 1611-25.

10 Proctor E, Chatamra K. High yield micronodular cirrhosis in the rat. Gastroenterology 1982; 83: 1181-90.

11 Raper SE, Baker ME, Burwen SJ, Jones AL. Isoflurane as an anesthetic for experimental animal surgery. Anat. Record 1987; 218: 116-22.

12 Higgins GM, Anderson RM. Experimental pathology of the liver. I. Restoration of the liver of white rat following partial surgical removal. Arch. Pathol. 1931; 12: 186-202.

13 Volkin E, Cohn WE. Estimation of nucleic acids. Meth. Biochem. Anal. 1956; 1: 287-305.

14 Grisham JW. A morphologic study of deoxyribonucleic acid synthesis and cell proliferation in regenerating rat liver: Autoradiography with thymidine- ${ }^{3} \mathrm{H}$. Cancer Res. $1962 ; 22: 842-9$.

15 Rasmussen TN, Jorgensen PE, Almdal T, Kirkegaard P, Olsen PS. Stimulatory effect of epidermal growth factor on liver regeneration after partial hepatectomy in rats. Scand. J. Gastroenterol. 1992; 27: 372-4.

16 Leffert HL, Koch KS, Moran T, Rubalcava B. Hormonal control of rat liver regeneration. Gastroenterology 1979; 76: 1470-82.

17 Prato SD, Kreutzenberg SV, Lisato G, Riccio A, Tiengo A. Mechanisms of hyperinsulinemia in hepatic cirrhosis. In: Francavilla A, ed. Liver and Hormones. New York: Raven Press, 1987; 15-21.

18 Meyer-Alber A, Hartmann H, Stumpel F, Creutzfeldt W. Mechanism of insulin resistance in $\mathrm{CCl}_{4}$-induced cirrhosis in rats. Gastroenterology 1992; 102: 223-9.

19 Simek J, Chmelar VL, Melka J, Pazderka J, Charvat $Z$. Influence of protracted infusion of glucose and insulin on the composition and regeneration activity of liver after partial hepatectomy in rats. Nature 1967; 213: 910-11.

20 D'Arville CN, Le MS, Kloppel TM, Simon FS. Alteration in the functional expression of receptors on cirrhotic rat hepatocytes. Hepatology 1989; 9: 6-11. 
21 Shankar TP, Drake S, Solomon SS. Insulin resistance and delayed clearance of peptide hormones in cirrhotic rat liver. Am. F. Physiol. 1987; 252: E772-7.

22 Richman RA, Claus TH, Pilkis SI, Friedman DL. Hormonal stimulation of DNA synthesis in primary cultures of adult rat hepatocytes. Proc. Natl Acad. Sci. USA 1976; 73: 3589-93.

23 Lee DC, Rose TM, Webb NR, Todaro GJ. Cloning and sequence analysis of a cDNA for transforming growth factor- $\alpha$. Nature 1985 ; 313: 489-91.

24 Mead JE, Fausto N. Transforming growth factor alpha may be a physiological regulatory of liver regeneration by means of an autocrine mechanism. Proc. Natl Acad. Sci. USA 1989; 86: 1558-62.

25 Noguchi $S$, Ohba Y, Oka T. The role of transcription and messenger RNA stability in the regulation of epidermal growth factor gene expression in regenerating mouse liver. Hepatology 1992; 15: 88-96.

26 Webber EM, Godowski PJ, Fausto N. In vivo response of hepatocytes to growth factors requires an initial priming stimulus. Hepatology 1994; 14: 489-97.

27 Fausto N. Hepatic regeneration. In: Zakim D, Boyer TD, eds. Hepatology: A Textbook of Liver Disease, Vol. 1. Philadelphia: WB Saunders, 1990; 49-65. 